\title{
Research on Online Commentary Characteristics of Xitang Homestay Based on Network Text Analysis
}

\author{
Zhang Danmei \\ Division of Tourism Management, Shanghai University School of Management, Shanghai, China
}

Email: $18817293087 @ 163 . c o m$

\begin{abstract}
This paper takes Ctrip's online reviews as the research sample, comprehensively uses ROST Content Mining 6 software and content analysis method to analyze the characteristics of visitors' comments after staying in Xitang homestay, in order to understand the core demand tendency of visitors to Xitang homestay. The study finds that, in terms of both positive and negative reviews, tourists pay the most attention to the facilities of the rooms, geographical location and service attitude of the landlord. Among them, they most concerned about the facilities of the rooms. On this basis, relevant suggestions are put forward to help improve the service quality of Xitang's homestay.
\end{abstract}

Keywords: Text analysis, homestay, commentary characteristics.

\section{Introduction}

As a new form of accommodation industry, homestay not only meets the needs of customers' accommodation and rest, but also enables customers to experience local customs. Homestay originated in Europe, and then spread to Japan and Taiwan, China. It has its own characteristics and sets off a wave of homestay boom. In recent years, with the rapid development of China's tourism industry and the advent of the era of national leisure and vacation, the number of vacationers has increased dramatically and the market demand has increased. The homestay industry in mainland China has also entered a period of rapid development, with explosive growth. More and more scholars have paid attention to the related issues of homestay accommodation ${ }^{[1]}$. Overseas research on the homestay industry is relatively rich and perfect, mainly focusing on stakeholders, homestay tourism industry, homestay business management and many other fields. The study of domestic homestay accommodation started relatively late. The main research contents include the current situation and problems of homestay accommodation development, the successful experience of excellent cases and the behaviour of homestay tourists.

With the advent of the era of "Internet \& tourism", people can buy products needed in the tourism process on the network platform before they travel, and they are keen to leave comments on the Internet after consumption. Network comment has become a form of expression of word-of-mouth propaganda after customer consumption. Some scholars at home and abroad have applied network text analysis to tourism research, focusing on tourism destination image, hotel service quality, tourists' perception, tourists' tourism motivation and so on. Choi et al. studied the image of Macao as a tourist destination by analyzing the content of various network information sources, such as official tourism websites, tour operators, travel agency websites, online travel magazines and guides websites and "blogs"[2]. Dincer et al. studied the unsatisfactory aspects of tourists by obtaining 424 negative comments from upstream visitors of Trip Advisor website on luxury hotels in Jordan, and put forward suggestions for improving the service quality of hotels ${ }^{[3]}$. Jansen et al.'s research shows that tourists mainly search for geographic information ${ }^{[4]}$. Chen Ning used the method of network text analysis to study tourists' accommodation experience in Longsheng Dazhai. He pointed out that tourists paid more attention to the geographical location of the accommodation, personalized service attitude, surrounding environment and characteristic catering services, and put forward some suggestions ${ }^{[5]}$. Zhang Qing used network evaluation to analysis the inadequacies of the service quality of rural homestay quarters in Nanyuan Mountains of Wuyi Mountains, and put forward suggestions ${ }^{[6]}$. Fu Yeqin studied the evaluation and feeling of Gulangyu tourism by analyzing donkey comments on online tourists ${ }^{[7]}$. Pi Changling et al. analyzed the complaints and comments of Gulangyu homestay tourists in Xiamen. The research shows that customer complaints focus on homestay facilities, services, overall evaluation, safety and hygiene ${ }^{[8]}$. Li Peipei analyzed the service 
quality of homestay accommodation around West Lake in Hangzhou, and put forward the methods to improve the service quality of homestay accommodation on the basis of the analysis ${ }^{[9]}$. Li Qian has studied the service quality of homestay quarters in Lanzhou by using network text analysis. The stud y points out that consumers pay the highest attention to the decoration style, indoor environment and the service attitude of homestay bosses. It also pays more attention to the hardware equipment of homestay quarters such as toilet, sound insulation effect and cost-effective ratio ${ }^{[10]}$.

On the basis of predecessors and from the point of view of network comment, this paper takes Xitang homestay quarters as the research object, and based on the information of network comment as the sample, extracts 300 good comments and 300 bad comments of Xitang homestay quarters respectively. Using Rost ContentMing6 software to extract high-frequency words and analyze data, this paper explores the characteristics of Xitang homestay tourists' online comments, and puts forward suggestions for the analysis conclusions.

\section{$2 \quad$ Research and Design}

\subsection{Research Subjects}

Xitang Ancient Town, located in Jiashan County, Jiaxing City, Zhejiang Province, is one of the six ancient towns in the south of the Yangtze River, and it is a thousand-year-old water town with Wu local culture. Xitang is known as a thousand-year-old town living. Xitang Ancient Town has been listed in the World Historical and Cultural Heritage Preparatory List. It is the first batch of famous historical and cultural towns in China and the national AAAAA scenic spot. The ancient water village in the south of the Yangtze River forms abundant natural landscape resources in Xitang. Streets are built by rivers and houses are built by water. It attracts millions of tourists every year, the homestay industry in Xitang ancient towns is also booming.

\subsection{Research Data Sources}

\subsubsection{Study sample selection}

This paper chooses Ctrip Travel Network visitor comment data as a sample. Ctrip Travel Network is the tourism e-commerce enterprise with the highest public brand awareness in China. At present, it is the largest online travel operator in China. Ctrip Travel Network Hotel Page is specially set up with "Inn and Homestay" column to facilitate the acquisition of sample data, and Ctrip Network stipulates that only real hotel subscribers can participate in Hotel reviews, and the evaluation content is real and reliable. Due to the large number of Ctrip users, the largest number of tourist reviews in China, and the large number of homestay accommodation in Xitang Ancient Town, this paper screens according to the following conditions.

1) Considering the timeliness and validity of the comments ${ }^{[11]}$, this stay chooses the comments from January 1, 2018 to January 1, 2019. And each comment has more than 30 words.

2) The homestay of Xitang Town should be concentrated in the scenic area of Xitang Town, and there are many types of homestay accommodation with different prices. The majority of homestay accommodation with housing prices ranging from 150 to 800 yuan occupies the majority. Therefore, the selected sample of homestay comment is based on the screening condition of Ctrip Online that the homestay accommodation is located in the scenic area of Xitang Town and the price is between 150 and 800 yuan.

3) Ctrip's Internet accommodation has a score rating, with a full score of 5 , and the visitors' comment mechanism also has a facial expression pattern, which corresponds to the four comment attitudes of "super stick", "good", "general" and "poor". This article chooses the first five reviews of 60 dormitories with 5 full marks and attitudes of tourists as "super-excellent" and "very good", totaling 300 reviews. Then, Choice the homestays with a rating of less than 4.5 and a visitor's comment attitude of "ordinary" and "poor" home, with a total of 300 bad reviews.

4) Considering the research methods, this study only chooses the narrative part, excluding comments such as poems and pure photo records.

5) Internet space has the characteristics of virtual, open and free. This study only uses the comments of 
tourists after living in person, and excludes the comments such as advertisement introductions and tips for tourists who intentionally publicize Xitang's homestay.

\subsubsection{Study sample pretreatment}

Due to the different background and language expression level of tourists, in order to better extract and analysis the text, this paper makes a simple text content pretreatment for the 600 comments.

1) Merging similar language expressions. The different names of synonyms, and the same place should be unified. For example, "WC" should be collectively called "toilet".

2) Exclude the irrelevant parts. Punctuation, emoticons, time pronouns, quantifiers, etc. are excluded from content analysis.

\section{$2.3 \quad$ Research Process}

\subsubsection{Word segmentation for samples}

The processed sample is saved as a plain text document with the extension of .txt and named as "Xitang Residence Excellent Review" and "Xitang Residence Bad Review". Then, the.Txt documents to be analyzed are imported into CM6.0 software, and all sentences in the text are divided into separate words, such as "room" and "hygiene", using the function of "word segmentation" in the software. After word segmentation, the system automatically names the documents "Xitang Residence Excellent Review - after word segmentation" and "Xitang Residence Bad Review - after word segmentation" for preservation.

\subsubsection{Revised word segmentation results}

Examine carefully the documents named "Xitang Residence Excellent Review - after word segmentation" and "Xitang Residence Bad Review - after word segmentation", correct the wrong and inappropriate word segmentation, such as the software automatically divides "Xitang" into two words "Xi" and "Tang", and merge them manually.

\subsubsection{Set up a filter vocabulary}

The common but not helpful words are included in the filter vocabulary, such as "one, one day, here, today, in, out" and so on.

\subsubsection{Compiling high frequency vocabulary}

Two text-only documents named "Xitang Homestay Excellent Review - after word segmentation " and " Xitang Homestay Bad Review - after word segmentation " are imported into the ROST Content Mining 6 software respectively. With the function of word frequency analysis, the system automatically generates the first 100 high-frequency words ranked from high to low. Through further manual processing and screening, the words unrelated to research are eliminated, and the top 30 high-frequency words related to research are selected.

\subsubsection{Drawing semantic network diagram}

Import the two text documents of "Xitang Homestay Excellent Review - after word segmentation" and " Xitang Homestay Bad Review - after word segmentation " into the ROST Content Mining 6 software, and use the function of "Social Network and Semantic Network Analysis" to obtain the Semantic Web Map of the online reviews of Xitang Homestay.

\section{$3 \quad$ Research and Analysis}

\subsection{Positive Comments Analysis of Xitang Homestay}

Through the high-frequency word extraction and the semantic network map analysis, it is found that the positive comments on Xitang homestay can be summarized into the following four aspects: room facilities, location, service attitude and customer experience. 


\subsubsection{Room facilities}

The primary function of homestay is to provide a place for rest. Among all the high frequency words, "room" is the highest frequency word, which is enough to show the tourists' attention to the room facilities. And among the good reviews about "room", tourists are most concerned about the "sanitation", "facilities" and "decoration" of the room. Tourists mainly mentioned that the Xitang homestay are clean and tidy, and has complete facilities, comfortable decoration and distinctive features.

\subsubsection{Location}

Key words such as "scenic spot", "location", "transportation", "geography" and "environment" are related to the location of homestay. Therefore, the location and the surrounding environment of homestay are also another main aspect that tourists pay attention to. Most tourists tend to live in the scenic area of Xitang ancient town, because there are many scenic spots and delicious food, which is convenient to visit. The homestay which are not far from the entrance of the scenic spot or located in the central area with convenient traffic, and of which the location is easy to find are also more attractive to tourists.

\subsubsection{Service attitude}

Comparing with chain hotels, the communication between customers and homestay landlords are more frequent and direct, and there are supposed to be more "human flavor". Good homestay landlords often make homestays emit greater charm and be much more popular for tourists. "Landlord" ranks the second most frequently used word, which fully shows that when tourists choose homestay, the service quality of the host of homestay is also the key consideration of tourists. The key words like "enthusiasm", "service", "attitude", "thoughtfulness" and "ticket" reflect the affirmation of tourists on the service of Xitang homestay. Good service attitude of homestay landlords will give tourists better feelings and deeper impressions, which will effectively improve the score for homestay operation. Among the good comments, there are many tourists commented that "The landlord is super nice, who introduced the scenic spots of xitang to us with great enthusiasm, recommended many delicious food, and bought the tickets for us, which let us save a lot of money...".

\subsubsection{Customer experience}

From the comments analysis of Xitang homestay, most tourists are satisfied with the accommodation experience in Xitang. High frequency words such as "like", "satisfied", "comfortable" and "good" express tourists' love for Xitang homestay. The high frequency words like "next time" and "recommendation" indicate that tourists have a high desire to choice Xitang homestay again.

Table 1. High Frequency Words of positive comments on Xitang homestay

\begin{tabular}{cc|cc}
\hline High frequency word & Frequency & High frequency word & Frequency \\
\hline Room & 275 & Complete & 57 \\
Landlord & 240 & Facility & 55 \\
Clean & 179 & Traffic & 54 \\
Scenic spot & 109 & Recommend & 53 \\
Enthusiasm & 106 & Like & 53 \\
Service & 105 & Satisfaction & 51 \\
Good & 104 & Warm & 47 \\
Position & 102 & Attitude & 44 \\
Convenience & 102 & Friends & 41 \\
Surroundings & 83 & Thoughtful & 41 \\
Hygiene & 74 & Be quiet & 40 \\
Inn & 68 & Ticket & 36 \\
Next time & 66 & Value for money & 36 \\
Tidy & 66 & Geography & 35 \\
Comfortable & 62 &
\end{tabular}




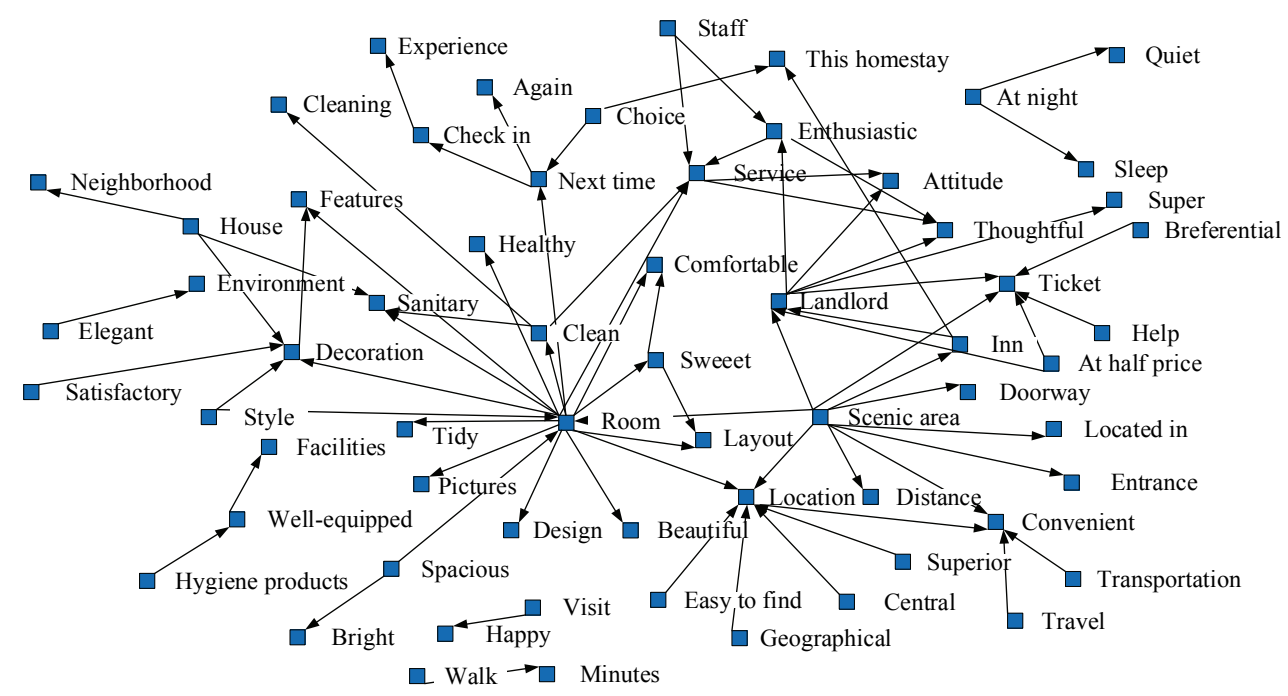

Figure 1. Semantic Web Map of positive comments on Xitang homestay

\subsection{Negative Comments Analysis of Xitang Homestay}

Through the statistical analysis of the high frequency words of the negative comments on Xitang homestay, it is found that the unsatisfactory points of the comments on Xitang homestay are mainly focused on three aspects: room environment, homestay location and service attitude of the landlord.

\subsubsection{Room environment}

Among the negative comments of homestay, "room" is still the most concerned point for tourists. Tourists' dissatisfaction is mainly manifested in the poor sanitary environment of the homestay rooms, dirty bed sheets and bedding, old facilities and equipment, small room area, poor soundproof effect, and insufficient hot water supply. Room environment is the core part of homestay, therefore, creating and keeping a clean and comfortable room environment is the most significant work in the management of homestays.

\subsubsection{Location}

High frequency words such as "location", "scenic spot" and "bar" indicate that tourists attach importance to the location of homestay. Tourists' dissatisfaction is reflected in the fact that some homestays are located outside the scenic area or even in remote areas, which makes the travel schedule very inconvenient. Moreover, some homestays are close to bars where there is a lot of noise, what's worse, most of them are rebuilt from houses with "poor sound insulation effect", which seriously affects the sleep quality of tourists at night. Xitang is a typical water town in the river south, where with abundant rainwater, and many Xitang homestay are built near the river for good scenery. Therefore, most rooms are damp, and there are many mosquitoes in summer, which also affects the accommodation experience.

\subsubsection{Service attitude}

"Landlord" is also a high frequency word of the negative comments on Xitang homestay. Generally speaking, the tourists feel that the service attitude of the landlord is enthusiastic. However, the text analysis points out that some homestay owners, especially during holidays, deliberately inflate the housing price and have a bad service attitude. And there are also some problems about dishonesty in operation, including requesting good reviews from tourists or even stealing customer passwords for high praise, inconsistent publicity pictures with real objects, which incurs the displeasure of tourists. 
Table 2. High Frequency Words of negative comments on Xitang homestay

\begin{tabular}{cc|cc}
\hline High frequency word & Frequency & High frequency word & Frequency \\
\hline Room & 246 & Moist & 57 \\
Boss & 187 & Disappointed & 48 \\
Bathroom & 128 & Ticket & 41 \\
Hygiene & 114 & Facility & 40 \\
Sound insulation & 109 & Service & 36 \\
Image does not match & 102 & Taste & 35 \\
Warm water & 102 & Bar & 31 \\
Scenic spot & 96 & Bad & 27 \\
Air conditioning & 93 & Simple & 25 \\
Position & 93 & Sound & 21 \\
Surroundings & 82 & Flip flop & 19 \\
Mosquito & 81 & Old & 17 \\
Attitude & 76 & Towel & 17 \\
Not clean & 64 & Area & 11 \\
Sheets & 57 & Attic &
\end{tabular}

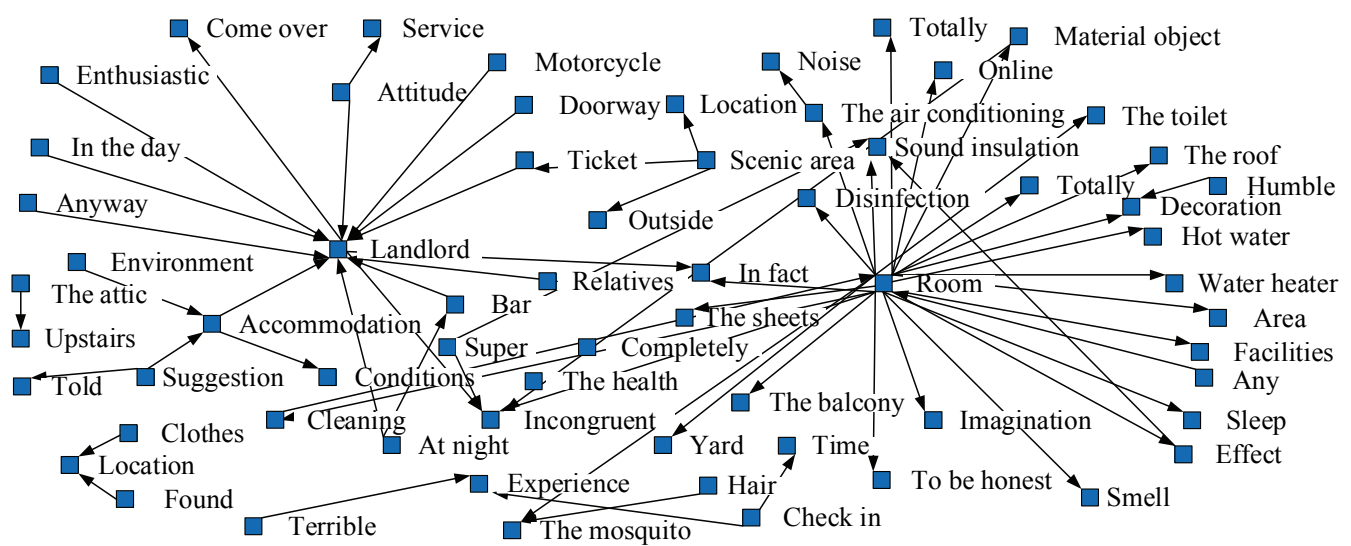

Figure 2. Semantic Web Map of negative comments on Xitang homestay

\section{Research Conclusions and Suggestions}

\subsection{Research Conclusions}

Comparing the analysis result of the positive and negative comments on Xitang homestay, it can be found that tourists have the same concerns when evaluating the homestays, no matter what the feeling was, which prove the accuracy of the statistical analysis. They are most concerned about the guest room facilities, the service attitude of the landlord and the location of the host family, among which the guest room facilities are the most concerned. In these aspects, Xitang homestay is easy to be loved by tourists, and it is also easy to get poor reviews.

\subsubsection{The room environment is the focus of the tourists' attention}

As the core of homestay, room facilities bring customers the most intuitive feeling and can best affect their experience. Tourists prefer clean and tidy rooms with complete facilities and equipment, as well as adequate hot water supply. In addition, the tourists also have higher requirements for sleep quality as well as the privacy requirement. Therefore, good soundproof effect of the room is also important. If these aspects failed to meet the expectations of tourists, it is easy to get tourists' aversion and dissatisfaction. 


\subsubsection{The location of Xitang homestay is also very important}

Most tourists visit Xitang in the ancient town, where most scenic spots and delicacies are. And the ancient town tickets are valid for only one day, which drives tourists to choose the homestay inside Xitang ancient town. There is a very busy bar street in the ancient town, where the noise is quite loud at night, which affects the normal rest of tourists, and it is also what tourists dislike. Therefore, tourists prefer to choose a quiet homestay with convenient transportation.

\subsubsection{Service attitude is also an important factor}

In general, the landlord of Xitang homestay provides warm and thoughtful service, and tourists have a high evaluation of the landlord's service attitude. However, according to the evaluation text, there also exist some chaotic phenomenons, especially during holidays. For examples, operators of homestay may deliberately increase the price of accommodation, have bad service attitude, and deceive customers. Moreover, the intimate and interactive communication between the landlord and the customer of Xitang homestay are relatively few.

\subsection{Suggestion}

\subsubsection{Improve accommodation facilities}

Homestay owners should try to improve the bathroom environment, remove peculiar smell in the room, and provide regular maintenance for air conditioning, exhaust fans, desk lamps and other equipment. Optimize interior decoration at the same time. The owner of the homestay should make full use of the characteristics of Xitang ancient town to decorate the homestay. Besides, mirror decoration can be used to expand the room space, dehumidifier or desiccant is helpful to reduce the room humidity, and soundproof devices can be added to enhance the soundproof effect. Moreover, the landlord of homestay should also often repel insects and mosquitoes, and prepare drugs for mosquito bites. Try to create a clean, comfortable, quiet, warm and harmonious environment with local characteristics for visitors.

\subsubsection{Provide convenient transportation services}

For the relatively remote homestay, the owner of the homestay should do a good job in transportation services, such as informing tourists of the homestay location and provide route guidance in advance, or provide shuttle service directly. All in all, do not make it difficult or inconvenient to reach the homestay, and the best choice of the homestay location is a place which is close to the scenic area and far from the noise source, with convenient transportation and good surroundings.

\subsubsection{Improve the service attitude}

Homestay owners must adhere to integrity, do not manipulate the network comments. The network publicity pictures of room should be consistent with the actual situation as far as possible, and should not be too beautified. Otherwise, it's easy for customers to have too high expectations, and results in the great gap between customer expectations and perception, which affects the accommodation feeling. The landlord should arrange the same type room as the customer booked, and extra charges for quilts or children should be notified in advance. When customers check out, the homestay should provide the bills positively. At the same time, the understanding and communication between the landlords and guests should be strengthened.

The joy of living homestay is to experience local life style and share life feelings. The operator of homestay shall be flesh and blood, and they should be good at sharing stories and experience, as well as interests, hobbies, and life attitude. According to the actual needs of customers, good operators provide services and help for the guests during their accommodation, so as to understand tourists and become friends.

From the results of network evaluation analysis, tourists are very concerned about "human care" service. Many visitors posted comments that said they had a "good chat with the landlord" or "the owner came to the station to pick up us ". Emotional service has become an important factor to attract customers and even improve the return rate of customers, which is also the core embodiment of homestay atmosphere. 


\section{References}

1. J. Jiang, Y. Li, "A review of domestic and international tourism "B\&B" research," Tourism Research, 2014, 6(4): $16-22$.

2. Choi S, Lehto X Y, Morrison A M. Destination image representation on the Web: content analysisof Macau travel related websites[J]. Tourism Management,2007,28(3):118-129 .

3. Dincer M Z, Alrawadieh Z. Negative Word of Mouse in the Hotel Industry: A Content Analysis ofOnline Reviews on Luxury Hotels in Jordan. Journalof Hospitality [J].Marketing \& Management.2017,26(8):785-804.

4. Jansen B J, Ciamacca C C, Spink A.An analysis of travel information searching on the web [J].Information Technology \& Tourism,2008,10 (2): 101-118.

5. Chen Ning. Research on B\&B Experience Based on Network Text Analysis— Taking Longsheng Dazhai as an Example [J]. Journal of Guangxi Vocational and Technical College,2018,11(01):78-82.

6. Zhang Qing, Sun Huaxi, Lan Zongrong, Yu Qiuyu. Analysis of Service Quality of Country Houses Based on Customer Network Evaluation_- Taking Nanyuanling Village B\&B in Wuyishan as an Example[J]. Journal of Xichang College(Social Science Edition),2018,30(02 ): 73-76.

7. Fu Yeqin, Wang Xinjian, Zheng Xiangmin. Research on Tourism Image Based on Network Text Analysis Taking Gulangyu as an Example[J].Tourism Forum,2012,5(04):59-66.

8. Pi Changling, Zheng Xiangmin. Study on Customer Complaints Based on Online Comments_— Taking Gulangyu Homestay in Xiamen as an Example[J].Tourism Forum,2017,10(03):35-44.

9. Li Peipei, Shan Wenjun. Study on the Quality Status and Promotion Strategy of B\&Bs around Hangzhou West Lake Scenic Area Based on Content Analysis[J].Modern Commerce,2017(18):28-30.

10. Li Qian, Yang Gui. The Countermeasures for Improving the Quality of B\&B Service in Lanzhou—Based on the Survey of Ctrip.com[J]. Journal of Huaihua University,2018,37(10):37-40.

11. Qiao Yufang. Research on Tourism Image Perception of Hohhot City [D]. Inner Mongolia Normal University, 2018.

12. Ma Lijun, Guo Liuliu. Study on the Demand Characteristics of Zhangjiajie Tourist Information Based on Network Text Content Analysis[J].Consumer Economy,2017,33(04):68-75.

13. Huang Pei, Chen Xueqiong. Study on Service Quality Evaluation of Tourism Place Inn Based on Content Analysis [J]. Journal of Xi'an University of Architecture \& Technology(Social Science Edition), 2017, 36(02): 36-41+91.

14. Xu Shuaishuai, Li Weiwei. The Quality Improvement Strategy of B\&B Service in Liaoning Province [J]. Resort Travel, 2019(01):56+58.

15. Hou Yuxia, Wu Zhongjun. Research on the Transformation and Upgrading of Ethnic Characteristic B\&B Based on IPA Analysis of Domestic and Foreign Tourists_- A Case Study of Pingshai Village and Dazhai in Longsheng County [J]. Social Scientist,2018(05):72-80

16. Deng Dingxian. Study on the Quality of B\&B Service Based on OTA Comments_— Taking Lijiang as an Example [J]. Economic Forum, 2017(09):112-115+135. 